\title{
Clinical History Matters, Skin Prick Test (SPT) Results are Not the Be-All and End-All for Allergy Diagnosis
}

\section{Taha A Qureshi | Afaq H Beigh | Iqra Jan | Fizalah Kawoosa | Shahid M Baba | Ayaz Gull | Nusrat Kounsar | Roohi Rasool Wani*}

*Correspondence: Roohi Rasool Wani

Address: Sher I Kashmir Institute of Medical Sciences, Soura, India

e-mail $\bowtie$ : Roohi_wani@yahoo.com

Received: 03 August 2021; Accepted: 17 August 2021

Copyright: (C) 2021 Qureshi TA. This is an open-access article distributed under the terms of the Creative Commons Attribution License, which permits unrestricted use, distribution, and reproduction in any medium, provided that the original work is properly cited.

\section{ABSTRACT}

The diagnosis of Allergic disease is combination of clinical symptom assessment and analysis of the gold standard Skin Prick Test (SPT). This case report stresses on the fact that the results of SPT have to be mandatorily associated with clinical symptom manifestation for which a detailed history taking is absolutely instrumental. This study represents the maiden case from India where a patient presented with SPT documented house dust mites (HDM) sensitization without typical clinical manifestations of the HDM allergy spectrum. The results of SPT prompted us to revisit the patient history more elaborately and it came to our notice that the patient was having a pet turtle and was allergic to one of the components present in the pet feed (Gammarus also know commonly as Shrimp) which cross reacts with some HDM allergens and hence the reactivity on SPT. A simple allergen avoidance strategy (here it was the pet and its feed) made a patient free from allergy symptom and off pharmacotherapy also.

Keywords: Skin Prick Test (SPT), House Dust Mites (HDM), Anaphylaxis, Gammarus, Pharmacotherapy

\section{Introduction}

Gammarus, also commonly known as shrimp is an integral part of seafood and is a crustacean belonging to the order Amphipoda that is not commonly used in in vivo allergy testing (SPT). It belongs to the genera of Crustaceans: Metapenaeus, Palinurus, Penaeus, Leander, Homarus or Pandalus (Fontán et al., 2005; Zhang et al., 2006). Freshwater shrimp constitutes indispensable biological feed in fish factories, poultry industry, animal husbandry and aquariophilia (Gamboa et al., 2000). To the best of our knowledge, till date no case of Gammarus as a cause of respiratory allergy has been reported from India. The present report describes a case of allergy to Gammarus, with respiratory symptoms.

\section{Case Report}

A 22 year old female presented with acute rhinitis (AR) from past six months was put on pharmacotherapy, symptoms are more indoors and there was no seasonal variation or any relation with dust exposure. Patient's evaluation was taken up which showed levels of total IgE $738 \mathrm{KU} / \mathrm{ml}, 6 \%$ of 
eosinophils and absolute eosinophil count (AEC) of 600. The Spirormetric parameters were normal with a pre forced expiratory volume in 1 sec (FEV1) of 92\% and FEV1/FVC of 84. Skin Prick Test with a standard panel of allergens including mites (Dermatophagoides), common local pollens like wild grasses, weeds, and trees, animal epithelia like cat and dog and moulds like Alternaria, Aspergillus, Penicillium and Cladosporium was carried out. Patient was positive to both D-pteronyssinus (19mm x 17mm) and Dfarinae $(22 \mathrm{~mm} \times 21 \mathrm{~mm})$. Since the positivity to these allergens was not clinically associating so well with HDM allergy clinical spectrum, whose typical manifestations are early morning predominantly indoor symptoms which aggravate on exposure to dust and contact with old clothings, carpets, etc. The patient's history was thoroughly revisited and revealed that she had adopted a pet turtle from last one year and was feeding it with fish food. The patient had earlier deliberately concealed this pet history fearing that she might be asked to do away with it. On checking the content-label of fish food, we found that it contained shrimp and other sea food waste contents. The patient was strictly advised to avoid the pet turtle and hence its food (which contained Gammarus), and to our pleasant surprise, only within six months of the avoidance, the patient became asymptomatic and has been off the pharmacotherapy from last three months.

\section{Discussion}

Major allergen present in shrimp known as "Pen a 1" can be considered the main component responsible for cross-reactivity with other invertebrate crustaceans, molluscs, arachnids and insects (Lopata et al., 1997; Lopata et al., 2016), and the patient evaluated in the present study only reacted to house dust mites as allergens of animal origin, we decided to study the implication of tropomyosin in possible immunological cross-reactions between Dermatophagoides and Gammarus. These results suggest that Gammarus sensitization which occurred in our case study was produced with the intervention of cross-reactions. From the above results we conclude that exposure to feed containing Gammarus freshwater shrimp was the main cause of the respiratory symptoms, similar findings were observed by Gamboa, et al. where they found the same antigen responsible for allergic reaction (Gamboa et al., 2000). This is the first case till date reported from India, the second most populous nation in which Gammarus allergy manifested itself as allergy to dust mite (in vivo diagnosis i.e. SPT) which could have easily misled a clinician towards treating dust mite allergy rather than true sea food allergy.

\section{Conclusion}

This is a classical example which does emphasise how a meticulous history taking and the clinical correlation form the corner stone for allergy diagnosis and that we must not get carried away by the strong positivity of SPT results. 
Acknowledgements: Not Applicable

Conflict of Interest: All Authors declare no conflict of Interest

Funding: No funding was received for the study

Consent of Ethics or Ethical Approval: The study was institutional Ethical Committee SKIMS

Consent of Patient: Detailed Consent was obtained from patient before the study was carried out

\section{References}

Fontán M, Añibarro B, Postigo I, Martínez J. Allergy to freshwater shrimp (Gammarus). J Investig Allergol Clin Immunol 2005; 15: 150-152.

Gamboa PM, Barber D, Jauregui I, Urrutia I, Gonzalez G. Allergic rhinitis to turtle food Asthma caused by a pet bat. Allergy (Copenhagen) 2000; 55: 405-406.

Lopata AL, Kleine-Tebbe J, Kamath SD. Allergens and molecular diagnostics of shellfish allergy. Allergo J Int 2016; 25: 210-218.

Lopata AL, Zinn C, Potter PC. Characteristics of hypersensitivity reactions and identification of a unique $49 \mathrm{kd}$ IgE-binding protein (Hal-m-1) in abalone (Haliotis midae). J Allergy Clin Immunol 1997; 100: 642-648.

Zhang Y, Matsuo H, Morita E. Cross-reactivity among shrimp, crab and scallops in a patient with a seafood allergy. J Dermatol 2006; 33: 174-177. 